\title{
Redesigning Computer-Supported Work Processes with Dual Information Systems: the Work Process Benchmarking Service*
}

\author{
Timo K. Käkölä \\ Department of Computer Science and Information Systems \\ University of Jyväskylä, FIN-40351 Jyväskylä, Finland \\ Tel.: +35850523 4165, Fax: +35814603 011, E-Mail: timo.kakola@cc.jyu.fi \\ Kalle I. Koota \\ Orion Corporation, Orion-Pharma, R\&D Information Systems \\ P.O. Box 425, FIN-20101 Turku, Finland \\ Tel.: +3582 2727665, Fax: +3582 2727510, E-Mail: kalle.koota@orion.fi
}

\begin{abstract}
The conceptual design of most computer-based information systems reflects a dualism of technology. During the development phase, part of the work-domain related knowledge is formalized and encoded in the software, making it difficult for users to reflect on and use this knowledge. This design/use-dualism contributes to the deterioration of the interpretive flexibility of information systems. We propose an information systems architecture called Dual Information Systems (DIS) that helps bridge the design/use dualism by providing organizations with a set of services that enable and reinforce both effective, institutionalized working and the questioning and (re)construction of computer-supported work routines. DIS have a four-layered conceptual structure: (1) people draw on the business layer to work and learn; (2) people use the breakdown layer to handle unexpected breakdowns; (3) self-organizing project teams use the project layer to create innovative work and IS (re)designs; and (4) the knowledge sharing server stores these redesigns and makes them organizationally available to facilitate working and learning as well as subsequent redesign efforts. In this paper, we first outline the theoretical background, conceptual design, and generic services of DIS. Next, we elaborate on the work process benchmarking service of DIS, which supports project teams in analyzing and redesigning computer-supported work through lateral sharing of knowledge of work processes between business units. Finally, we demonstrate the benchmarking service with the help of the ReDIS prototype.
\end{abstract}

KEY WORDS AND PHRASES: Dual Information Systems, interpretive flexibility, Knowledge Creation Nets, organizational creation of knowledge, organizational interfaces, work process benchmarking, work process enactment and redesign, work process modeling

Information technology can be seen as constructed by human agency and as institutionalized in structure [46]. Orlikowski [46] calls this "the duality of technology." Duality implies that organizations can use information technology as a source of working and learning if agents ${ }^{1}$ can use and modify the technology whenever it is necessary to redesign computer-supported work practices, and if the technology can be institutionalized as a legitimate component of the organizational working and learning environment.

Unfortunately, many organizations today suffer from dualistic, institutionalized computerbased information systems (IS) that hide the constructed nature of IS from agents [33]. They (1)

\footnotetext{
* Timo Käkölä is responsible for the theoretical development of this paper. Both authors contributed equally to Section "The ReDIS Prototype and its use in Redesigning Work Processes". Kalle Koota programmed the ReDIS prototype.

1 We use the word "agent" to refer to people whose work is computer supported. We want to avoid the term "user" since that term connotes that information systems could be used and studied independently of other types of work.
} 
limit lateral communication, coordination and knowledge sharing; (2) provide little feedback to agents (especially in the lower echelons of an organization) on work arrangements and on the coordination and communication patterns which emerge from their use; (3) limit the agents' ability to reflect and inquire within the social and technical contexts in which the agents are embedded, restraining them from creating, questioning, and modifying practical knowledge when problems emerge; and consequently (4) endanger the process of reinvention that any complex technological artifact should undergo when put to use [12]. For instance, changing the computersupported work processes through user-driven work and IS design is almost impossible unless agents thoroughly understand the content and organization of work [26]. This design/use dualism of many IS is the problem to be addressed in this paper.

Organizations would benefit from an information systems architecture that bridges this dualism and taps the resources and capabilities of all agents to enable organizational working and the creation and sharing of knowledge. Orlikowski [46] provides neither a powerful conceptual model nor practical guidelines to help organizations design such an architecture. This paper continues the efforts of Käkölä [33], [34] to do so. We will call the architecture Dual Information Systems (DIS).

Käkölä [33] complemented Orlikowski's work by drawing on a frame of reference called the act-oriented perspective [17]. This perspective helps transcend the design/use dualism by interpreting the functions and memory provided by computer software as an inseparable component of the work of the responsible, knowledgeable people using the software [44]. It also helps agents even on the shop floor level gain a comprehensive understanding of their work, its computer-supported parts, and its relationship to the business as a whole. In light of the actoriented perspective, a necessary but insufficient condition for any computerized system to qualify as a component of DIS is that it helps agents develop such an understanding.

However, Käkölä's work [33], [34] had two important limitations. First, well-developed local understanding of work is necessary but not sufficient for improving work. Second, the information systems architecture needed to align information systems with the act-oriented perspective would be expensive to build. For example, traditional integrated information systems hide their constructed nature to the extent that they often appear to agents as acting, knowledgeable subjects rather than media and outcomes of work [17]. The redesign of these systems to reflect the act-oriented perspective would unlikely be attractive to organizations if the benefits from the redesign were limited to understanding better "what is." To become fully applicable, DIS also need to help the agents on the frontline establish and join project teams, in which they collaborate with middle managers to (1) share knowledge of their computer-supported work processes and practices laterally within and between business units; (2) draw on their improved knowledge and skills to improve their own performance; and (3) create new, shared stocks of knowledge and crystallize this knowledge into work processes and practices that exceed the expectations of customers, realize the visions of top management, and create good jobs.

The purpose of this paper is to remedy these limitations and meet the design requirements stated above. The paper outlines the conceptual design of DIS to enable and reinforce both effective, institutionalized working and the questioning and (re)construction of computersupported work routines on individual and organizational levels. But no conceptual design can help transcend the design/use dualism without supporting organizational processes and structures. Therefore, this paper also aligns the conceptual design with the organizational design called "hyperknowledge organization" that, when enacted, supports the use of knowledge at work and the creation of new knowledge to reconstruct work. These normative designs are expected to help organizations produce productive interaction or "fit" between organizations and DIS. This "fit" is productive when these interactions facilitate both the efficient enactment and effective reconstruction of computer-supported work. 
The paper elaborates on the work process benchmarking service of DIS. This component of the conceptual design supports work process redesign through lateral sharing of knowledge of work processes between business units. The service is crucial from the viewpoint of the implementation of the conceptual design of DIS in organizations. It enables redesign project teams leverage organizationally the knowledge that other (act-oriented) services of DIS provide locally to help agents work and theoretically understand their work, and thus makes the conceptual design of DIS both more solid theoretically and more attractive to practitioners. The work process benchmarking service is demonstrated with the help of the artifact constructed, the ReDIS prototype. The paper describes benefits that the redesign project teams of an imaginary financial services organization could expect by using ReDIS.

Dual Information Systems thus denote the information systems architecture for hyperknowledge organizations. The architecture provides services defined in the conceptual design of DIS. These services help transcend the design/use dualism by facilitating shared knowledge creation and use in the context of routine work and redesign work. The services (1) conceptually unite manual and computerized aspects of work, thus helping agents to understand the holistic nature of their work, including its computerized aspects; (2) let agents zoom in on the details of their work practices and check shared databases for mistakes in order to deepen their knowledge and fix many breakdowns locally; (3) help agents draw on their improved knowledge of work designs to enter and interact in redesign project teams where they can share knowledge of computer-supported work practices so that best practices can be created and crystallized into work redesigns; and (4) store the created design knowledge in the organizational knowledge base so that it can later be used to enact, reflect on, and reconstruct work practices.

This paper proceeds as follows. The Section "The Theoretical Background of the Conceptual Design of DIS" delineates the theoretical background of DIS. The Section "Dual Information Systems and Computer-Supported Work" first outlines the conceptual design of DIS and the services DIS offer project teams to enable the redesign of computer-supported work processes. Next, it elaborates on the work process benchmarking service of DIS. Finally, it discusses the use of work and software process modeling in Dual Information Systems. The Section "The ReDIS Prototype and its use in Redesigning Work Processes" uses a case study to illustrate the hyperknowledge organization design and demonstrates the benchmarking service of DIS and its benefits with the help of ReDIS. Conclusions are stated and issues for future research are discussed in the last section.

\section{The Theoretical Background of the Conceptual Design of DIS}

To design Dual Information Systems, a comprehensive theoretical understanding of the role of IS in organizational working, the creation of knowledge, and learning is necessary. We recapitulate the work of Orlikowski [46], Nurminen [44], and Nonaka [43] in this section to provide the theoretical background of the conceptual design of DIS. 


\section{Duality of Technology, Interpretive Flexibility, and Time-Space Disjuncture}

Orlikowski [46] introduces three concepts that are central to this paper: the duality of technology, its interpretive flexibility, and time-space disjuncture. The duality concept is derived from the duality of structure that forms a key concept in Giddens' structuration theory [18], [19], [20]. Giddens [19] distinguishes between system and structure in his analysis of social systems. He regards social systems as patterned social relations reproduced across time and space through the actions of human agents. Structure provides for the binding of the social relations into social systems. Social systems have structural properties that are drawn upon in social interaction. Roberts and Scapens [49, p. 446] state:

Through being drawn on by people, structures shape and pattern (i.e., structure) interaction.

However, the structures themselves are reproduced only through interaction. This is the 'duality of structure'; it is in this way that structures can be seen to be both the medium and the outcome of interaction.

This recursive, continuous process is what Giddens calls structuration.

The duality of technology concept sees information technology as a structural property that is enacted by human agency and institutionalized in structure. Designers produce a technology to provide resources and rules by creating and encoding work-domain related knowledge into it. Agents socially construct a technology by assigning it different meanings and using it flexibly in their work. But technologies usually become institutionalized mediums of work over time because agents cannot continuously reinterpret or physically modify them, if the agents are to accomplish their work efficiently.

The duality of technology recognizes that "technologies are products of their time and institutional context, and will reflect the knowledge, materials, interests, and conditions at a given locus in history" [46, p. 421]. However, the dual nature of IS is masked by the time-space disjuncture arising from the various phases (e.g., design, implementation, and employment) of interaction between a technology and organizations. Within and between these phases, the actions constituting the technology are separated temporally and spatially from the actions constituted by the technology.

According to Orlikowski [46, p. 421], the time-space disjuncture "is collapsed . . . by understanding that technologies have different degrees of interpretive flexibility." This emphasizes that "there is flexibility in how people design, interpret, and use technology, but that this flexibility is a function of the material components comprising the artifact, the institutional context in which a technology is developed and used, and the power, knowledge, and interests of human actors ..." as well as time [46, p. 421]. Orlikowski summarizes the causality between the time-space disjuncture and the interpretive flexibility of technology as follows [46, p. 421]: "The greater the temporal and spatial distance between the construction of a technology and its application, the greater the likelihood that the technology will be interpreted and used with little flexibility."

\section{The Design/Use-Dualism of Information Systems: Implications and Alleviations}

The interpretive flexibility of information systems is often poor [7], [16], [46], [65]. This inflexibility results in part from agents with insufficient shared knowledge of: (1) the nature of social practices as a whole; (2) the articulation of these practices in time and space by the structural properties of organizations; (3) their own roles in the organization; and (4) the role of information systems as a structural property mediating work processes. 
One important reason for their lack of awareness is that the conceptual and material structures of computer software typically reflect the design/use-dualism of technology; during the institutionalized use of an IS the constructed nature of the IS is masked by the software. Dualistic information systems separate symbolic information from the material and social systems the symbols represent, hide the processing rules and retention structures in the software and database schemas, and blur the role of people as the producers and consumers of information [8], [44].

The prevalent dualistic structure and poor interpretive flexibility of IS have several costly implications. Agents are restricted to using functions expressed in the software [30, p. 390]. They also face considerable difficulties monitoring their actions since they cannot fully interpret and validate the meaning of information produced by the dualistic, "black box" systems, and they cannot see and feel the outcomes of their computer-supported actions [65, pp. 79-96]. Because of their limited ability to control all aspects of work, including computerized tasks, the agents cannot necessarily be responsible for their work as a whole. Finally, the agents' ability to intervene in and transform existing social practices is limited because they cannot easily criticize and challenge the interpretations, resources and norms embedded in the algorithms and databases of the IS [37], [46].

But agents can regain control of their jobs in computer-supported work environments. Orlikowski [46, p. 418] states:

... knowledgeable and reflexive human agents are capable of altering the controlling influence of the technology. The extent to which individuals modify their use of technology, however, depends on whether they acknowledge its constructed nature. This is determined by the degree to which individuals can recognize the mediating role of technology, can conceive of an alternative beyond it, and are motivated to action.

Thus, agents' ability to control their work depends on their domain and technology-related skills and knowledge as well as the shared stocks of knowledge that inform them about their own and other agents' roles and normatively regulated and sanctioned behaviours [37], [65].

We summarize the relationships between the time-space disjuncture, the design/use-dualism, and the interpretive flexibility of IS as follows: The greater the temporal and spatial distance between the construction of an IS and its application and the greater the conceptual separation of the IS from agents and their work during design, the greater the likelihood that the IS will be dualistic (i.e., it will be institutionalized and its constructed nature will be hidden from agents) and that it will be interpreted and used with little flexibility.

The conceptual separation between dualistic and Dual Information Systems is necessary because it has clear implications for information systems design. For example, the redesign of a dualistic software package to incorporate customizable functions and sophisticated support systems will likely increase the interpretive flexibility of information systems built on the software. But if the conceptual design of the software continues to separate computerized and non-computerized aspects of work, this redesign does not necessarily result in such services of Dual Information Systems that help agents theoretically and holistically understand their work.

The maximum benefits of DIS are unlikely to be realized unless the application of the conceptual design and services of DIS transcends the design/use dualism, and thus helps agents control and redesign their work as a whole, including its computer-supported aspects. For this purpose, DIS can bridge the time-space disjuncture (1) vertically (between users and designers) by providing services that help users understand the constructed nature of software partly constituting and partly constituted by users' work; and (2) horizontally (between work groups and business units using similar technologies) by providing services that help users redesign work processes in project teams in collaboration with professional designers and users from other functional groups and business units. In the following subsections, we outline two possible conceptual solutions to build these bridges. 


\section{Act-oriented Perspective: Toward DIS on the Level of Human Agency}

The time-space disjuncture between the design and use of IS and the dualistic nature of computer software imply that the users often cannot see the link between their work as a whole and its computerized parts. Because Orlikowski's work [46] is descriptive, it does not provide a conceptual solution to uncover this missing link.

The first author has used the act-oriented perspective [17], [44] to provide a solution [33], [34]. This perspective states that IS cannot be separated from agents' work because no IS can serve as a conscious actor. Therefore, software modules should be designed so that they can be interpreted as computerized tasks that have one or more responsible human agents. Conceptually, each agent has his or her own information system; receiving, memorizing, processing, and transmitting the information necessary for his or her work.

The act-oriented perspective bridges the time-space disjuncture vertically by seeing the knowledge encoded in software by designers in time-space context $\mathrm{A}$ as the acts of the responsible agents in time-space context $\mathrm{B}$. Once this bridge is functioning, information systems are no longer symbol systems and texts constituting their own reality and treating agents as passive information processors. Rather, IS become truly constitutive of organizational realities that can be flexibly interpreted, understood, enacted, and reconstructed by agents.

Yet, the perspective is not fully in line with the duality of technology. It operates on the level of human agency and emphasizes agents' need and ability to control their work and IS, but it does not address organizational creation and sharing of knowledge as a way to create new computer-supported work practices. In this sense, act orientation favors the institutionalized character of information systems and organizations. Moreover, in the act-oriented perspective, all agents are seen as knowledge workers who need to be able to control the specialized knowledge, rules, and resources embedded in their IS to the same extent as they control the manual aspects of their work. The assumption of the bounded nature of responsibility and control partly aligns the perspective with the traditional bureaucratic view. But this control over knowledge creates increased opportunities to learn skills and create new knowledge that transcend boundaries, and thus considerably expands the authority of workers in the lower echelons. Unless tied into strict bureaucratic rules, the perspective could yield an organization managed from the bottom-up in which entrepreneurial agents and small self-organizing groups would create and apply knowledge. Coordination of work and sharing of knowledge would be difficult because the key visions and norms sanctioning and justifying joint action would be missing or chaotic; no central authority would exist; and information would be dispersed and difficult to use. It is unclear how the act-oriented perspective alone could help organizations resolve or use this contradiction between increased opportunities to (re)construct meanings and work practices and the requirement of tightly bounded work and knowledge structures.

In summary, the paradox of act orientation is that it requires a bureaucratic structure to function well but simultaneously makes agents aware of the weaknesses of this structure by revealing how rigidly working and learning is governed by the organizational and technical rules and resources. We accept the perspective as a basis for Dual Information Systems but we are not satisfied with the functional bureaucracy or bottom-up driven groups as the best organizational forms for DIS. Dual Information Systems call for an organizational design that successfully combines the beneficial aspects of bureaucratic and group-based forms and eliminates their weaknesses. Nonaka [43] has developed an organizational design prototype called hypertext organization to help organizations realize such a combination. This design is described in the next section. 


\section{Hypertext Organization Design: Toward DIS on the Organizational Level}

Different business units and organizations use similar information systems. They develop a variety of interpretations of these systems and their suitability in supporting work, and construct a variety of work designs which these systems are used to support. The horizontal time-space disjuncture between the business units using IS implies that the systems and organizations interact in unforeseen ways, yielding a number of more or less effective computer-supported work arrangements. These arrangements, when shared and evaluated, can serve as a source of new knowledge for work redesign. By creating, maintaining, and sharing knowledge of various work arrangements and their effectiveness, organizations can ensure that the best practices proliferate. Dual Information Systems can play a central role in these processes.

To understand what kind of shared knowledge creation and use processes and structures Dual Information Systems must support to stimulate work process redesign, we draw on Nonaka's [43] theory of organizational creation of knowledge. Nonaka [43] presents several conditions that enable organizations to create and share knowledge, two of which are of special interest here: redundancy and breakdowns.

No matter how well people do their work, routines may break down unexpectedly. Agents face two challenges in breakdown situations. First, they must get their routines back on track as quickly as possible. Second, they must develop and test multiple hypotheses about what went wrong to ensure a lasting solution [65]. In this respect, breakdowns play a fundamental role in stimulating the creation of knowledge [25], [43], [63].

Redundant information, which is defined as "the existence of information more than the specific information required immediately by each individual" [43, p. 28], also accelerates the creation and sharing of knowledge. The sharing of 'extra' information makes it easier for agents to recognize their place in an organization, interact, develop a common direction, create new concepts, enter each others' area of operation, provide advice, and even do each other's jobs if necessary. "In short, redundancy of information brings about 'learning by intrusion' into an individual's sphere of perception" [43, p. 28].

Redundancy can be built into organizations in many ways. Internal competition in work process improvement and product development is one effective method [43]. Indeed, overlapping work arrangements can form a key resource for organizations if they are cleverly exploited. When knowledge pertaining to these arrangements is externalized into explicit, redundant information, these arrangements can be shared, evaluated, and improved within and across organizations. Moreover, we expect that the application of act orientation to unite computerized and noncomputerized aspects of work processes contributes to the sharing and improvement of computer-supported work because both aspects of processes then constitute a holistic unit of analysis. The DIS architecture can have an instrumental role in helping organizations externalize their (partly overlapping) computer-supported work processes and store the resulting representations of work in knowledge repositories so that they can be shared and analyzed organizationally for internalizing and reconstructing work.

How can organizations create and rapidly shift between contexts of interaction where responsibility for the present and for the creation of future work practices are equivalently sanctioned and enacted? Nonaka [43] proposes 'hypertext organization' as an organizational design prototype that helps design such contexts. Hypertext organization is a dual organizational structure: it "coordinates the allocation of time, space, and resource within the organization" [43, p. 33] so that an organization can achieve high performance in routines and simultaneously ensure long-term survival by creating and applying new knowledge. DIS have the same dual purpose: facilitation of effective routine work and redesign work. Therefore, the maximum 
benefits of DIS would more likely be realized if the conceptual structure of DIS reflected the hypertext organization structure.

Hypertext organization is formed by the dynamic combination of hierarchically organized business units and self-organizing project teams that pursue the equivocal visions of top management by drawing on and accruing an organizational knowledge base. Nonaka [43, pp. 3233] states:

The core feature of the hypertext organization is the ability to switch between the various 'contexts' of knowledge creation to accomodate changing requirements. . . . Each context has a distinctive way of organizing its knowledge creation activities. . . . Hypertext organization design first distinguishes the normal routine operation conducted by a hierarchical formal organization from the knowledge creating activities carried out by selforganizing teams. . . . By establishing the most appropriate organizational setting for the two activities, an organization can maximize the efficiency of its routine operation, which is determined by bureaucratic principles of division of labor and specialization, and also the effectiveness of its knowledge creation activities.

(Insert Figure 1: "Hypertext Organization - An Interactive Model of Hierarchy and Nonhierarchy [43, p. 34]" about here.)

Hypertext organizations are comprised of three layers; knowledge-base, business-system, and project-system (Figure 1). The 'knowledge-base' layer "embraces tacit knowledge, associated with organizational culture and procedures, as well as explicit knowledge in the form of documents, . . computerized databases, etc." [43, p. 33]. Normal work routines are enacted by a formal, bureaucratic organization in the 'business-system' layer (hereafter "business layer"). The 'project-system' layer (hereafter "project layer") provides a field of interaction where loosely linked project teams create knowledge.

In a hypertext organization, knowledge is created through the circular movement of agents among the three layers. Members of project teams are selected from different functions and business units across the business layer. They interact with the knowledge-base layer at the bottom and make an 'inventory' of the knowledge acquired and created in the project layer. "After categorizing, documenting, and indexing the new knowledge, they come back to upper business-system layer and engage in routine operation until they are called again for another project" [43, p. 33].

From the viewpoint of this paper, the hypertext organization as a theoretical organization design model is flawed: because the model is highly abstract, it pays little attention to technology. It views technology as a form of explicit knowledge stored in the knowledge-base layer. It views practices in general (including those where technologies are designed and deployed) as forms of organizational tacit knowledge. Nonaka does not explicitly address interactions between technologies and work practices.

However, hypertext organization design is implicitly in agreement with the duality of technology because it views technologies and practices as shared stocks of knowledge and their development and use as a continuous creation and exploitation of knowledge. The act-oriented perspective can also be enacted effectively. The business layer relies on a bureaucratic division of work that allows clear assignment of responsibilities even for computerized pieces of knowledge in the knowledge-base layer. The project layer together with redundant information allow people leverage on their improved knowledge of work as a whole, and thus reconstruct work when necessary. In the following section, we propose a conceptual design of DIS to make explicit the connection between DIS and hypertext organizations. 


\section{Dual Information Systems and Computer-Supported Work}

The primary purpose of the Dual Information Systems architecture is to enable and reinforce both effective, institutionalized working and the questioning and (re)construction of computersupported work routines. Designing such an architecture is a complex undertaking. Thus, it is beyond the scope of this paper to examine in detail all the services that might be critical for the architecture to meet this purpose. In the following subsection, we outline our proposal for the conceptual design of DIS and use it to propose a new organizational design called "hyperknowledge organization", thus providing readers with an understanding of the context in which this paper will develop more detailed design guidelines for certain services of DIS. The next three subsections describe the four structural components of the conceptual design. This section concludes with a detailed discussion about work process benchmarking and modeling services that critically enable and are enabled by DIS.

\section{The Conceptual Design of DIS and the Hyperknowledge Organization Design}

In accordance with the hypertext organization design, the structure of the proposed conceptual design of DIS has three primary layers (Figure 2): (1) agents on the business layer continuously draw on the business layer of DIS to learn, enact, and coordinate activities in business units; (2) self-organizing project teams on the project layer use the project layer and the knowledge sharing server of DIS to produce innovative work and IS (re)designs that can be enacted on the business layer; (3) the knowledge sharing server of DIS is a repository of explicit work and IS design knowledge in the knowledge-base layer of a hypertext organization. In addition, there is the breakdown layer of DIS that agents on the business layer can use to zoom in on the details of their work and to deepen their understanding of the computerized aspects of work in order to handle unexpected (coordination) breakdowns.

(Insert Figure 2: "The conceptual design of the DIS architecture in a business unit of a hyperknowledge organization" about here.)

We elaborate the hypertext organization design into the organizational design called "hyperknowledge organization." The hyperknowledge organization design enables and is enabled by the conceptual design of DIS. Hyperknowledge organizations have a set of business units on the business layer. Each business unit of a hyperknowledge organization has a functional internal division of labor. The information systems architecture of each business unit follows the conceptual design of DIS, and each has significant autonomy over how it conducts business and uses information systems. The business units compete internally and are rewarded (or sanctioned) for their performance, work process innovations, and the adoption and development of these innovations by other units. Project teams share knowledge within and between business units to redesign work processes of individual business units. The Section "The ReDIS Prototype and its use in Redesigning Work Processes" illustrates the hyperknowledge organization design.

\section{Business and Breakdown Layers of DIS}

Käkölä [33] presented the Embedded Systems Approach (ESA) to instantiate the business and breakdown layers of DIS in a business unit into Embedded Application Systems [17], which follow the act-oriented structure. They enable the effective enactment of computer-supported 
routines in business units. In a continuous knowledge-creating spiral, ESA relies on and enables the project teams of the hyperknowledge organization. The teams develop new concepts of computer-supported work and share them among the business units. Work processes of each unit are externalized, visualized, and memorized by using organizational and software process modeling formalisms. Process models serve as the building blocks of the organizational interface of each unit through which the computerized tasks and knowledge encoded in Embedded Application Systems become inseparable components of the agents' working and learning environment. We use the term "organizational interface" [38] because the conceptual design of the business and breakdown layers of DIS fundamentally transcends the traditional concepts of human-computer interface and human-computer interaction by focusing on how agents act, interact and learn by drawing upon various structural resources and rules, including Embedded Application Systems, and thus partly sustaining and partly modifying their computer-supported work.

The business layer of DIS also helps hyperknowledge organizations routinely collect quantitative and qualitative work process information that can be used for work process benchmarking and redesign in the project layer. Breakdown management services let agents audit trail and zoom in on the details of their work process, check shared databases for mistakes, and fix many breakdowns locally. Additional learning services can be provided in work situations in which process models are not sufficient to help people fully internalize the complexities of work.

The services of the business and breakdown layers of DIS are described in detail and demonstrated with Embedded Application System prototypes in [33], [36].

\section{Work Process Redesign through the Project Layer of DIS}

Embedded Application Systems and their process-model based organizational interfaces transcend the design/use dualism by modeling and visualizing both manual and computerized aspects of work processes as an inseparable whole. But traditional dualistic software products are less expensive to build and faster to replicate because they require little or no attention to modeling and visualizing the noncomputerized aspects of work contexts where these products will be used. Organizations might not be willing to invest large sums of money in Embedded Application Systems and organizational interfaces if the primary benefit from these investments was agents' improved understanding of work. Investments become much more attractive when the knowledge encoded in these systems and interfaces can also be leveraged to create and share new work routines and practices.

The project layer of DIS helps members of redesign project teams draw on the other components of the architecture to reconstruct work processes of their business units. Project teams in a hyperknowledge organization have strategic relevance for business units and the organization as a whole. They have broad authority to design their work themselves. They also have extensive resources available to ensure that they can afford the gradual conceptualization, crystallization, and justification of new computer-supported work designs without being burdened by impossible deadlines and other constraints. The members typically include representatives from each functional group within a business unit to ensure that the voice of the frontline is heard. Middle managers serve as project managers when top managers set a new direction.

The project layer of DIS offers middle managers personnel management services to make it easier to staff project teams with the best people and to guarantee the adequate breadth and depth of knowledge. The layer also provides project management services that help middle managers coordinate projects internally and meet project deadlines. While we recognize the importance of 
both personnel and project management, those services are outside the scope of this paper. We focus on services that we expect to be of more importance for all team members.

The project layer of DIS provides at least the following services for project teams:

- Argumentative dialogue services

- Benchmarking services

- Modeling services

- Simulation services

- Authoring services

The analysis of work processes and the conceptualization of work-related dilemmas and objectives in the business units are supported through argumentative dialogue services. Nonaka [43, p. 25] states: ". . . dialectic is a good way of raising the quality of dialogue. . . Through the use of contradiction and paradox, dialectic can serve to stimulate creative thinking in the organization." These services promote free and candid expression of ideas and concepts as well as constructive criticism validated by reasoned arguments; both are key conditions for the effective creation and sharing of knowledge [1], [35], [43].

The refinement of these concepts into a thorough understanding of one's own work process(es), its weaknesses and strengths, and possible design solutions are supported through benchmarking services. The benchmarking services of DIS are divided into two services: financial and work-process benchmarking. Financial benchmarking service [61], [62] helps teams initially screen business units and collaborating organizations with high financial performance, and thus potentially effective work practices. Work process benchmarking service (the focus of this paper) enables business units to autonomously develop and share competitive work arrangements. These services thus provide redundancy of information, foster constructive, internal competition between business units, and help units bridge the time-space disjuncture horizontally.

Work and software process modeling services support the crystallization of these design solutions into a testable work and information systems redesign congruent with ESA [33], [48]. Hyperknowledge organizations depend critically on effective modeling of computer-supported work practices. On the business layer of DIS, organizational and software process models help agents understand and perform their routines. On the project layer of DIS, the models are used to analyze and benchmark work processes, to crystallize the knowledge created into new work processes that unite computerized and noncomputerized aspects of work, to simulate and negotiate these processes, and to make the processes available for the business layer and subsequent redesign projects. This dependency requires modeling languages to have a number of features. We will elaborate in Subsection "Process modeling and Dual Information Systems."

Simulation services allow the testing of the proposed redesigns. Simulation is especially effective to estimate and refine the performance of the redesigned computer-supported work processes. Work and IS designs unlikely to meet performance goals can be eliminated before implementation. These services are a central component of the DIS architecture because simulation links the design and implementation of work processes and thus helps bridge the timespace disjuncture vertically [21].

Argumentative dialogue services also support constructive negotiation over the rules and resources specified in the redesign as well as the simultaneous monitoring of the negotiation process itself [35]. These services are essential because the redistribution of responsibilities and the related resources and rules involved in redesign may trigger embarrassment and threat [1]. If organizations cover up these social processes or use information systems to bypass them, the formation of social defenses will likely accelerate and the creation of knowledge deteriorate [35]. 
Authoring services support the design of learning services that nurture the internalization and enactment of the redesign in the business layer of DIS. They are complementary to modeling services. They are likely to utilize multimedia and virtual reality authoring technologies that have more bandwidth than process models to capture and represent knowledge embedded in the physical actions of agents and in organizational ecology (e.g., the physical layout of a production line). Authoring services play a central role in bridging the time-space disjuncture vertically because process models are necessary but not always sufficient to provide people on the business layer of hyperknowledge organizations a comprehensive understanding of work.

In summary, the combined dialogue, simulation, and authoring services help business units and the organization as a whole ensure that much of the deterioration of the interpretive flexibility that results from the time-space disjuncture can be anticipated and eliminated during design. Modeling services support the act-oriented perspective and help unite the IS designs conceptually with people and their work designs.

\section{The Knowledge Sharing Server of DIS}

The knowledge sharing server (KSS) of DIS is a repository of explicit work process knowledge in the knowledge-base layer of a hyperknowledge organization. KSS is conceptually outside the boundaries of the business units. It holds both current and historical work process knowledge. The primary levels of analysis in KSS are the work process(es) of each business unit. Individuals and their performance should not be of interest to redesign project teams. Therefore, KSS need not include information on individual agents. In the long run, collaboration with other businesses is beneficial so that KSS can also store information about these collaborators. Knowledge sharing across organizations helps increase internal diversity.

KSS provides project teams in different business units with access to the organizational interfaces, work process performance information, and Embedded Application Systems of the business units. The primary structural properties of work designs in KSS are work roles, documents used or produced by agents in these roles, and Embedded Application Systems and their databases. The services of the project layer of DIS capture information created by project teams directly at the point of creation. When a project terminates, the knowledge can be easily edited, and then stored in and shared through KSS.

While KSS is intended to provide agents and project teams with redundant information, the conceptual design of DIS does not require physical redundancy of information. Agents together with middle management are responsible for the quality of information they produce in the business layer. Similarly, the project teams are responsible for the computer-supported work designs they create.

KSS should be seen as an index of organizational knowledge with links to the organizational interfaces and other sources of information in the business units. Agents using the different layers of DIS in a business unit can follow these links to sources of information in other business units, and thus internalize redundant information, enlarge their own knowledge, and create new concepts to improve their computer-supported work in a hyperknowledge organization.

\section{The Role of Benchmarking in Redesigning Work}

We have outlined the conceptual design and services of DIS on a relatively high level of abstraction. While readers need an overall understanding of the design and services, more elaborate description of certain services helps stimulate further research and practical applications of the DIS architecture. Hyperknowledge organization design, with its multiple autonomous business units and KSS that helps these units share knowledge, provides excellent 
support for an important redesign method called benchmarking. Therefore this paper focuses on the benchmarking services. In this subsection we explain what benchmarking is, why effective benchmarking in the project layer is critically dependent on the services provided by KSS and the business layer of DIS, and what are the benefits from benchmarking that provide significant incentives for organizations to develop DIS by following the conceptual design of DIS. Section "The ReDIS Prototype and its Use in Redesigning Work Processes" presents an implementation of the benchmarking services.

Spendolini [57, p. 9] defines benchmarking as "a continuous, systematic process for evaluating the products, services, and work processes of organizations that are recognized as representing best practices for the purpose of organizatonal improvement." It has become a standard method of business management [23], [24], [39], [41]. Benchmarking is a company-internal process in which the activities of a given company or business unit are measured against the best practices of the best-in-class companies [3], [40], [55], [56]. It aims to close the gap between "us" and "them."

A systematic method for performing benchmarking was first developed in the USA by the Xerox Corporation [10], [11], [59]. Benchmarking is an integral part of organizational culture for many companies [5], [45], and its use is increasing rapidly [6]. It can be divided into a number of subconcepts. Zairi [64] has developed a wide concept that brings benchmarking close to the concept of quality assurance. In his hierarchy, the subconcepts are internal benchmarking, competitive benchmarking, functional benchmarking and generic benchmarking. Schmidt [52], [53] divides benchmarking into three main categories: strategic benchmarking, customer benchmarking and cost benchmarking. Jennings and Westfall [29] bring traditional benchmarking close to strategic success. They divide strategic benchmarking into three different subconcepts: customers, competencies and competitors. All of these subconcepts attempt to describe different characteristics and their relations to the same overlying concept, i.e. benchmarking.

We focus on work process benchmarking, which analyzes how products and services are designed, manufactured, marketed, and serviced internally and in the best-in-class companies. It is a vital tool for work process redesign. It stimulates thinking "out of the box," that is, away from the institutionalized work patterns reinforced by the personal histories and work experiences of managers and workers [57]. It helps motivate and justify the need for improvement by showing that things can and should be better. It provides practical ideas on how to improve. It extends the scope of benchmarking from a management method to a joint resource for organizational learning that involves non-management workers.

This subconcept of benchmarking is harder to implement than those which focus on outcomes, products or financial results because gathering process information is a complex task that cannot be done from a distance. Consequently, organizations often fail to use work process benchmarking in enough detail [27, p. 400]. However, the business layer of DIS naturally provides at least internal work process information. The benchmarking services together with the knowledge sharing server of DIS both critically depend on and directly support the use of this information for benchmarking. This mutual dependency and support between the different layers of DIS thus motivates the development of all layers as we have envisioned.

The use of the benchmarking services of Dual Information Systems should not be limited to top-down, management-driven benchmarking. The creation and sharing of knowledge cannot be the responsibility of management alone. Consequently, we make the following methodological assumptions. (1) A project team is established to carry out benchmarking and redesign. (2) Middle manager(s) responsible for the work process under redesign and the representatives of workers responsible for individual process steps play a central role in the project. After all, they know the process ("what is") best and will be responsible for implementing the changes. They also have the expertise to compare their own procedures with others. (3) Top management 
ensures that the project can and will yield results, thus bringing the company closer to "what should be."

(Insert Figure 3: "The main steps of work process benchmarking" (adapted from [60, p. 23]) about here.)

Figure 3, which outlines the generic steps involved in work process benchmarking [60], assumes top managers are in charge. We adapt it to meet our previously stated assumptions. (1) Benchmarking begins by identifying the target process(es) most critical for success, the customers of this process and their expectations. This is relatively easy because the benchmarking project team itself is an important customer, it knows the other customers well, and the target process is their own work. The team determines how well expectations are met, and if necessary, establishes special requirements to meet or exceed these expectations. (2) The team identifies a best-in-class company that excels in this process, figures out how to get information about the process, and determines what can be learned from it. (3) It develops a thorough understanding of the target process, its performance, the phases involved, and the technologies and methods that enable or constrain the process. This step is also relatively easy because the business and breakdown layers of DIS have already helped team members develop such an understanding. (4) The team collects and analyzes information about the work process of the best-in-class company to understand how the company measures the performance of the process, which factors enable the performance, and what could prevent the application of their process. (5) The team analyzes the nature and magnitude of the performance gap to understand which characteristics of their process are superior. (6) It decides which improvements to implement immediately, in the short term and the long term. (7) It determines which characteristics of the benchmarked company and process should be adapted to meet the immediate and short term goals; what changes in culture, work process, and performance metrics are implied; how these changes can be implemented; and finally implements them. (8) It empowers the entire workforce to internalize, enact, and reflect on the new process so that the workforce can both work effectively and prepare for future projects that bring long term goals nearer.

The work process benchmarking service of Dual Information Systems supports project teams in all these steps.

\section{Process Modeling and Dual Information Systems}

How can redesign project teams develop organizational interfaces to enable effective working, benchmarking, and learning through smooth navigation in DIS? Most traditional structured systems analysis and design approaches are ill-suited to the development of organizational interfaces because (1) they focus almost exclusively on modeling data flows, data structures and other components of technical systems and (2) the models are difficult for agents to understand and use [4], [13]. These modeling languages reinforce the development of dualistic, reified information systems [15, p. 12], [33].

Fortunately, process modeling languages [2], [13] remedy many of the weaknesses of the technically oriented modeling languages. Curtis, Kellner and Over state [13, p. 75]: "Process modeling is distinguished from other types of modeling in computer science because many of the phenomena being modeled must be enacted by a human rather than a machine." Käkölä [33], [34] analyzed different process modeling languages and found the Role Interaction Net process modeling language [48] is reasonably effective in alerting people to the dual nature of 
information systems. Drawing on this research, we have developed the Knowledge Creation Net (KCN) language [31], [32].

The KCN language is based on organizational role [51], [58] and knowledge creation theories [43], Petri nets [47], and Role Interaction Nets [48]. In accordance with role theory, the language provides two primitives: roles and interactions. A $\mathrm{KCN}$ is composed of a set of concurrent roles. The behaviour of a role is described by its solitary actions and its interactions with other roles. Unlike the RIN language, the KCN language also describes how knowledge is created, shared, and converted in interactions between agents. This helps clarify the dual nature of information systems. People create and share tacit and explicit knowledge through the processes of socialization, externalization, combination, and internalization [43]. Computerized systems enable and constrain these processes by combining existing knowledge according to the rules and procedures encoded into these systems by people in earlier time-space contexts. This distinction between what people do and what computers "do" can be made explicit when the Knowledge Creation Nets are employed in DIS. Figure 4 clarifies a few basic notations of the KCN language.

(Insert Figure 4: "Some notations of the KCN language" [31], [32] about here.)

Techniques from Petri nets are used to give the language process description and enactment capability. Enactment capability means that the $\mathrm{KCN}$ models project teams design using the modeling services of DIS can be directly executed on the business layer of DIS if the technical implementation of the layer supports direct execution [48]. This is vital for DIS. First, contrary to static models, executable models provide organizations with clear incentives to maintain them. Second, executable models can be used both to measure the performance of work processes and to capture deviations between the specifications and the way work is really done. Consequently, work process benchmarking is facilitated, the variances in performance and the underlying reasons for these variances can be quickly identified and fixed, and specifications can be updated to reflect improved work practices.

Models are always abstractions. Even process modeling can thus detach agents from their organizational and social setting and treat work itself as a sterile assemblage of tasks, roles, and interactions. For that reason, relying on process modeling alone in Dual Information Systems would be oversimplification. Additional learning services such as multimedia training sessions should be provided on the business and breakdown layers of DIS to help agents understand their work and quickly learn efficient work patterns. However, their further investigation is beyond the scope of this paper.

In summary, we expect the conceptual design of DIS to increase the value of work process modeling significantly. Modeling is no longer something separate from work. When representations of work are a cornerstone of the organizational interfaces of DIS, agents become accustomed to these representations as an integral part of their work routines. The models become more meaningful, the interpretive flexibility of technology improves, and the justification of routines can be questioned more quickly. When agents know not only tacitly their work but also the explicit models representing work, they can more easily enter and take a reflexive, responsible role in the project layer of a hyperknowledge organization. 


\section{The ReDIS Prototype and its Use in Redesigning Work Processes}

In this section, we present the ReDIS ${ }^{2}$ prototype to illustrate how the redesign of work processes is supported by the benchmarking service of Dual Information Systems. Käkölä and Koota [36] describe the business and breakdown layers of ReDIS. The case organization and the work process described in the following subsections are fictitious, but the ideas stem partly from the IBM Credit Corporation case presented by Hammer and Champy [22]. The case study gives ample opportunity to illustrate the hyperknowledge organization design and to research the development and use of DIS to support shared creation of knowledge in the context of work process redesign. The ReDIS project was conducted in a laboratory environment. Personal computers and the Microsoft Access ${ }^{\mathrm{TM}}$ system [28] were selected as the development platform.

\section{The Case Organization and its Credit Issuance Process}

In accordance with the hyperknowledge organization design, we make the following assumptions about the case organization and the role of ReDIS in the organization. (1) The Credit Corporation is a subsidiary of a much larger organization. (2) Issuing credit effectively is important for the organization as a whole because financing customers' purchases can be extremely profitable. (3) The Credit Corporation is divided into business units that issue credit within their regions. (4) The units can autonomously decide how to conduct their operations. (5) The units compete internally, and are rewarded for their performance, work process innovations, and the adoption and development of these innovations by other units. (6) ReDIS systems support each business unit locally. The systems are connected by a wide area network run by a centralized knowledge sharing server that is accessible to all units.

We focus on one unit. Its credit issuance procedure is as follows (see the upper left corner of Figure 5). After negotiating a sale, a sales agent in the Sales unit externalizes the tacit knowledge resulting from the negotiation by writing a standardized credit request and sends the request electronically to the Credit unit for the region. The Embedded Credit Application System (ECAS), the computer system used for credit issuance, automatically receives the request and stores it in its data base. The next available credit checker opens the request by using ECAS and checks the creditworthiness of the customer. If he rejects the request, ECAS sends it back to the sales agent. The next available modifier and pricer modify an approved, standard loan contract to meet customer requirements and determine the interest rate, respectively. ECAS then combines information in the priced request with a standard quote letter information that a clerk uses to finish the credit issuance. Finally, ECAS stores the quote in its data base and sends the quote letter to the Sales unit.

Workers in different roles are responsible for their own work. If they face a problem they cannot solve, they can seek help from "specialists," who are typically employees with more experience and expertise. Relying on a specialist slows down the procedure but is sometimes unavoidable.

Different characteristics of a credit issuance process such as time, quality, and expense are measurable by analyzing the following "key figures:"

- Number of people involved

- Average rate of arrival of credit requests

- Percentage of requests that require specialists' assistance

2 The ReDIS project (1994-1996) was led by Timo Käkölä at University of Turku, Finland. 
- Percentage of rejected requests

- Percentage of issued credits leading to cancelled deals

- Average cycle time

- Average request processing time

- Percentage of issued credits leading to credit losses

- Average profit margin of credits

In addition, each process step is measured by analyzing:

- Number of people involved in the step

- Average request processing time

- Average queuing time for the step

- Percentage of requests that require a specialist's help

These figures are used for all units. Units can use their own measurements, too, but only ones that are used for every unit are recognized by the benchmarking service of ReDIS. When new more relevant figures arise, or some prove to be unimportant, the use and weighting of these figures in ReDIS can be re-evaluated.

These measurements are used as benchmarks to continuously improve the credit process and to periodically redesign it. Such analyses might lead, for example, to smaller staff size (cost characteristic), reduced need for specialists' assistance (cost and time characteristic), a smaller number of unnecessarily rejected requests and cancelled deals (quality characteristic), improved profit margins (profitability characteristic), and shorter cycle times (cost and time characteristic). Of course, it is practically impossible to measure the absolute success of any given process because of the many variables. For example, the process could be fast but require a large staff and lead to many cancelled deals. But it is possible to use these measurements to examine the strengths and weaknesses of the process from multiple perspectives, and thus acquire valuable knowledge to improve and redesign work processes.

\section{The Main Components of ReDIS for Work Process Redesign}

The organizational process models constructed using the $\mathrm{KCN}$ language serve as the organizational interfaces of the units in the business layer of ReDIS. The organizational interface of each unit has four basic functions. First, it provides agents in certain work roles with rolecentric views of ECAS. In accordance with the act-oriented perspective, these views let agents see both the manual and computerized parts of their work as a whole, and thus carry out their responsibilities. For example, the view for credit checkers uses detailed KCN models to help credit checkers understand their entire domain of responsibility: the types of documents they use and produce (credit requests, checked requests, accepted requests, and rejected requests); the software modules of ECAS that implement their computerized tasks; and their manual and computer-supported tasks [36]. Second, agents can use the organizational interface to enact their computerized tasks simply by clicking the KCN symbol associated with their role. Third, it provides a full-fledged working and learning environment where agents can navigate, run different types of queries, and internalize redundant, real-time information about the unit, its work process design and performance, and ECAS. Fourth, it provides access to the breakdown and project layers of ReDIS.

The business layer of ReDIS collects performance data from each process enactment and stores it in the unit's local server. The procedural and descriptive chunks of knowledge visualized by the $\mathrm{KCN}$ models are also stored in the server. The server is implemented as a relational data base that holds all relevant information about the unit, agents associated with certain work roles, the process design, and process enactment (the number and characteristics of agents in different 
roles, and the interactions that occur during the process). Naturally, all the relational tables accessed by ECAS are part of this data base.

The benchmarking service provides redesign project teams with an effective way to visually and interactively compare the performance of different units. The key figures of the process of each unit are calculated from the server of each unit and stored into the work process benchmarking table located in the knowledge sharing server. The $\mathrm{KCN}$ design of the overall credit issuance process of each unit is also stored in the benchmarking table. The project teams can thus compare the processes and performance of different units by scanning the benchmarking form of ReDIS. Two instances of the form are used in Figure 5 to show the KCN-based organizational interfaces of two units. The benchmarking data can be examined from a number of perspectives. For example, the units can be ranked based on the average cycle times of their processes.

(Insert Figure 5: "Work process benchmarking between two business units" about here.)

It is also possible to use the benchmarking service of ReDIS to explore a particular unit in more detail. Project teams can probe a unit to develop a comprehensive understanding of the underlying reasons for the unit's current performance. This design implies that members of a redesign project team must be able to access the servers and navigate the organizational interfaces of other units through the knowledge sharing server.

\section{Using the Benchmarking Service of ReDIS in a Credit Process Redesign Project of Credit Corporation}

Periodically, business units set up projects that aim to redesign their own work processes. The redesigns are typically evolutionary rather than radical. But because the services of the project layer of ReDIS are meant to shorten the cycle times of individual redesign projects, successive projects can yield radical changes quickly. A project is begun by selecting suitable workers from all the different roles in the process. The head of the unit serves as the project leader. Information system expert(s) also take part. The project team members are then "lifted" from the business layer to the project layer.

The first phase is to analyze the strengths and weaknesses of unit's own work process to develop a deep, shared understanding of it, and to conceptualize the area(s) where the process should be improved. The project team enters the project layer of ReDIS and uses its benchmarking service to open the benchmarking form (the upper left corner of Figure 5) and examine the work process performance of their own unit by means of a set of key figures. These figures reflect the characteristics of the units and their work processes that are deemed crucial for effective performance. The project team compares the key figures to those of the benchmarking average form (the upper right corner of Figure 5) that uses KSS to give for each characteristic the average performance of all the units within the organization. After comparing their own performance to the averages, the project team decides to concentrate on shortening the average cycle time of their process - the characteristic where they are the least competitive.

The benchmarking service then uses KSS to filter other units on the second benchmarking form according to the average cycle times of the process (Figure 5). This makes it easier to find units whose process designs are the most innovative, and thus most likely to help achieve the goals of the redesign project. Finally, the project team finds a unit whose process seems intriguing (the lower right corner of Figure 5). The unit has a shorter average cycle time with about the same number of staff and without sacrificing quality. 
Why is their process superior? Interestingly, the $\mathrm{KCN}$ model suggests that the other unit has learnt to exploit the interpretive flexibility of its ECAS much better than the target unit. By slightly tailoring its ECAS, the unit has combined the roles of the modifier and the pricer into a single role called "handler." Another significant difference between the units is in the use of specialists. The successful unit uses the specialists to assist only in the most critical process step: checking the creditworthiness of the customers. The staff is apparently well trained, judging by the fact that the lack of specialist help does not seem to slow down the process steps or lower the quality of the process as a whole.

The project team uses KSS to access the organizational interface of ReDIS in the superior unit in order to investigate details like (1) how different process steps are carried out in the unit, (2) what are the special instructions related to them, (3) how much and what kind of training the staff has received, and (4) what kind of working and learning support is provided by the organizational interface. During this detailed analysis it is especially rewarding to have a representative from each work role in the project team. The professional skills and experiences of each representative can be fully leveraged when probing each process step. The examination indicates that the unit has indeed provided extensive training and that this investment is paying off.

Encouraged by the benchmarked unit's positive results, the project team decides to increase the training in their unit. The team realizes that average cycle times may increase slightly at first due to the higher expectations for individual workers. However, the extra training and experience will eventually lead to learning, and the cycle times can be expected to shorten significantly. Combining the roles of the modifier and the pricer seems wise as well. The roles are closely related and need similar information. Moreover, the handlers in the benchmarked unit are clearly able to handle their responsibilities. So why split them? The team decides to raise slightly the price of their credit because the benchmarking information shows that even though the average interest rate of the credit is higher than that in the units in general, the average percentage of cancelled credit contracts is not.

Finally, the redesign is implemented. The modeling services of the project layer of ReDIS are deployed to update the organizational interface of the business layer of ReDIS so that it reflects the new work process design, to tailor the modification and pricing modules of ECAS, and to update the local server so that the names of the agents responsible for the "handler" role are known. The personnel of the redesigned unit, especially the handlers, is also trained properly. Members of the project team play a crucial role in training because only they can share their tacit knowledge accumulated during the project with agents in the business layer. However, the conceptual design of ReDIS reduces the need for training because much of the explicit computersupported work design knowledge created by the project team is already available to agents in easily understandable form through the organizational interface and ECAS.

When training has advanced enough, the redesign is instantiated and enacted in the business layer of DIS. The redesign is also stored into the knowledge sharing server for later use in other work redesign projects of the Credit Corporation. In this way, ReDIS helps the corporation share the knowledge created by the project team across various organizational levels and units. This phase may require extensive editing to ensure that people in other units can flexibly interpret knowledge in KSS. These people are more dependent on explicit knowledge in KSS than the agents in this unit because the former lack many cultural, tacit aspects of work that are selfevident to the latter. Yet, agents in other units must not be overloaded with irrelevant knowledge.

In summary, the changes made by using the benchmarking service of ReDIS are expected to yield (1) better exploitation of the interpretive flexibility of ECAS as a result of a fairly small reconstruction; (2) lower percentage of requests requiring specialists' assistance; (3) shorter average cycle time; (4) lower variable costs; (5) increased average profit margin of the credits issued; and (6) more meaningful jobs for the agents who will assume the new handler role. Points 
(2) and (3), when combined with continued quality in the other aspects of the process, are likely to increase customer satisfaction, and thus lead to fewer cancelled deals. Additionally, workers' job satisfaction and productivity tend to increase when work is more varied and challenging [42]. As a result of these improvements, the unit should become substantially more profitable.

\section{Reflections}

The example presented in this section has illustrated the potential benefits of the conceptual design of DIS and especially its benchmarking service in work process redesign projects. First, we have shown how a system following the conceptual design supports an innovative, "double loop"-reinterpretation of information technology. The project team has flexibly interpreted work roles, tasks, and the role of ECAS in enabling and coordinating these roles and tasks. But this very reinterpretation of the use of ECAS in the business unit has resulted from the reinterpretation of knowledge encoded in the project layer and KSS of ReDIS through the use of ReDIS! Second, we have shown, how DIS can support rapid co-evolution of (1) work processes and their supporting technologies (here the credit issuance process and ECAS) within a business unit, thus reducing the time-space disjuncture vertically, and (2) work processes between business units of a hyperknowledge organization, thus reducing the time-space disjuncture horizontally. Within a unit, the business layer of ReDIS brings the work process model into life by uniting the model with its enactment through the organizational interface. This feature supports the overall understanding of both manual and computerized aspects of the unit's work process and provides a real-time window to its status and performance. The strengths of systems like ReDIS are even more obvious when the sharing of knowledge between business units is focused on. The reader can imagine the project, and its magnitude, that would be needed to gather consistent, thorough, and up-to-date information about the work process designs and benchmarks of, say, twenty other business units and collaborators without the services of ReDIS. Once the conceptual design of DIS has been implemented in an organization-wide IS architecture, the benchmarking service provides this information to all the units whenever they need it.

However, if project teams apply the benchmarking service mechanistically, the drawback of the service and the conceptual design is the likely convergence of work processes between business units. The more the designs of computer-supported work processes converge, the fewer novel insights can be gained by sharing them, thus increasing the degrees of their institutionalization. At least two strategies should be employed to tackle this challenge. First, project teams should learn to identify and focus on different characteristics of processes and then innovatively apply them. When used in this way, the strength of the benchmarking service is that there never exists just one best-of-the-breed unit with a process that is "as good as it can get" in all characteristics. Even with effective co-evolution of processes, different units are particularly good with respect to certain process characteristics. Therefore, all units have something to learn from others, which gives each unit the opportunity to continually improve its performance. In the example of this section, even the benchmarking business unit is expected to serve as a model of a successful unit in some characteristics for the other units - including the one that was superior now. Second, as already mentioned in Section "The Knowledge Sharing Server of DIS," close collaboration with other businesses is vital for hyperknowledge organizations to guarantee the flow of new ideas.

When a system such as ReDIS is introduced in an organization, it easily causes confusion among workers. Questions such as "Is this yet another way to control us?" and "What is the benefit to us if our work is not only being monitored but also widely shared and copied?" can arise. A key issue in making these questions disappear is to convince the workers that such 
managerial control focuses on general results rather than on precise measurement of work steps. In an organization that is truly committed to becoming a hyperknowledge organization, the message from the management should be that it is not out to unilaterally control individual workers, but to look for good working habits that could be shared among units. In addition, a generous bonus-system should be used to motivate units to share their knowledge. For example, in the case of this section, the redesign project is carefully documented in ReDIS. This is done for future reference in other redesign projects, but also to be able to recognize and reward the workers of the benchmarked unit for their excellence.

The maximum benefits of the DIS architecture are unlikely to be realized unless organizations learn to change the basis of organizational control from mistrust that triggers unilateral managerial control over workers toward negotiated control [35] where managers and workers trust each other and can negotiate rules and resources openly and constructively. Käkölä [35] discusses the importance and difficulty of achieving such organizational learning processes in detail and proposes guidelines for designing information systems that foster negotiated control instead of unilateral control.

\section{Conclusions and Future Research}

Insufficient knowledge of work practices and the role of IS in enabling and conditioning these practices, especially among non-management workers, reduces the interpretive flexibility of IS. Insufficient knowledge results, in part, from the design/use-dualism of technology: during the institutionalized use of IS their constructed nature is partly hidden from people. Consequently, we offered the conceptual design of Dual Information Systems, a conceptualization of an information systems architecture for hyperknowledge organizations that transcends this dualism. On the level of human agency, the design collapses the time-space disjuncture between the development and use of information systems vertically by interpreting all the computerized tasks and chunks of knowledge encoded in computer software as the work and knowledge of the people using the software. On the organizational level, the design helps transcend the dualism (1) vertically by allowing people to draw on their improved knowledge in order to shift between routine work and redesign work effectively, and (2) horizontally by facilitating the management of co-evolution of IS and organizational routines across organizational and functional boundaries.

This paper has made contributions in three areas: (1) generic design principles for the DIS architecture; (2) generic design principles for hyperknowledge organizations that would enable and be enabled by DIS; and (3) specific design principles for work-process benchmarking that leverage the structural properties of DIS and the hyperknowledge organization design.

The paper has identified several generic IS design principles to bridge the design/use-dualism of IS and thus reach and maintain high interpretive flexibility of information systems. First, it is fruitful to focus design on three conceptual layers of DIS, the project, business, and breakdown layers, as well as the knowledge sharing server. Second, the design must help agents quickly and easily enter the project layer to redesign computer-supported work processes. Finally, the design must accelerate the knowledge-creating spiral by helping organizations store and share work process redesigns through knowledge sharing servers.

The paper has developed the hyperknowledge organization design: Nonaka's hypertext organization design augmented by autonomous business units and DIS. A hyperknowledge organization is formed by the dynamic combination of hierarchically organized business units with functional internal division of labor, self-organizing project teams, and organizational 
knowledge base. Project teams and business units of the hyperknowledge organization use the services of DIS to draw on and accrue knowledge in the knowledge sharing server of DIS. The business layer provides a social context where act-oriented information systems of the business and breakdown layers of DIS are used for routine work and breakdown management. Project teams provide a social context for work redesign where constructive dialogue, benchmarking and other services of the project layer of DIS are used. The interactions of hyperknowledge organizations and DIS are likely to be productive: technologies and other structural properties of social systems can be enacted and modified effectively.

The organizational and information systems design guidelines presented in this paper are important contributions but they are not sufficient. They should be crystallized into a form solid enough to allow further development, testing, and criticism in order to foster the accumulation of knowledge in information systems research. The ReDIS Prototype is one such crystallization. However, crystallizing all the services of DIS was outside the scope of this paper. Because work process benchmarking is an important method for process redesign and can excellently leverage the hyperknowledge organization design (e.g., its autonomous business unit structure) and DIS (e.g., KSS and the process model-based organizational interfaces), we illustrated the work process benchmarking service of DIS to provide significant incentives for organizations to develop DIS by following the conceptual design of DIS.

This paper, like any piece of research, has its limitations. One is that the conceptual design of DIS has not been validated. The breadth and complexity inherent in the conceptual design have prohibited this research from building a single prototype system that would cover all the components of DIS and enhance agents' working, creation of knowledge, and learning. Future research is needed to find out to what extent agents are able to use the explicit knowledge provided by the business layer and the knowledge sharing server of DIS to effectively redesign their computer-supported work with the project layer of DIS.

Another limitation of this research is that we have not suggested ways to alleviate challenges faced in the implementation of DIS. Many issues of a technical and organizational nature must be resolved when Dual Information Systems are implemented. Redesigning flexible and generic work processes is almost impossible if organizations do not maintain precise knowledge of their structures, processes, and systems [9], [14], [49]. But many organizations today have difficulties even maintaining the consistency of the databases of their production systems. DIS require organizations to capture, define, and represent consistently not only data but also the work processes, artifacts used or produced, and work roles in which agents enact the processes. Additionally, the employment of work process benchmarking requires the measurement of process performance with comparable yardsticks. Consequently, future research should help practitioners create process modeling, definition, and measurement standards within and between organizations.

The designers of DIS must be aware of the complexity of organizational knowledge creation and sharing processes, and not simply focus on adding ever more intelligent support services into DIS. Otherwise, DIS are subjected to the same risks of reification and institutionalization as other technologies. Evaluation and redesign of computer-supported work should be seen as a complex social process where human agents create a variety of potentially conflicting interpretations [54]. Therefore, we have concentrated less on the technical issues and more on the ways the benchmarking service should support the project teams to create such interpretations and act to help agents and business units better exploit the interpretive flexibility of Embedded Application Systems in the business layer of DIS. Finding out the extent to which benchmarking as a social process could be further supported, for example by the argumentative dialogue services of the project layer of DIS, is an interesting topic for future research. 
The DIS architecture plays a crucial role in maintaining, using, and augmenting organizational intelligence inseparably intertwined in the agents, structures, processes, and information systems of hyperknowledge organizations. It is also applicable in many types of work and organizational contexts. For example, work process benchmarking and modeling are generic methodologies that can be applied in manufacturing as well as office environments.

Our research design has not allowed us to empirically evaluate the feasibility and viability of the radical organizational redefinition proposed in this paper. But the application of socially rich theories of situated organizational-historical context in our designs provides excellent foundations for future evaluation in the field. Empirical research is necessary to experiment with the conceptual design of DIS and its methodological underpinnings in different work contexts. These experiments will provide theoretical insights that help organization scientists and information systems researchers refine the hyperknowledge organization design and the conceptual design of DIS so that these designs can be enacted productively in different contexts. They will also provide guidelines that help practitioners appropriate and leverage these designs and underlying methodologies.

Future research is also needed to assess and validate the utility of the work process benchmarking service of DIS by developing and testing systems like the ReDIS prototype first in the laboratory and later in the field. Earlier research of the first author indicates that a system like ReDIS can be very useful for work and work redesign. First, process model-based organizational interfaces help people understand their work as a whole [34]. Second, benchmarking is vital for continuous improvement of work [61]. Third, useful computer-based working and learning environments can be built for benchmarking purposes [61], [62]. Consequently, we are confident that Dual Information Systems in general, and their work process benchmarking service in particular, offer substantial benefits to organizations that implement them to increase the interpretive flexibility of information systems even in the lower organizational echelons.

\section{Acknowledgement}

We are grateful to Inger Eriksson and Markku Nurminen, whose visions about Embedded Application Systems inspired our research, to Hannu Vanharanta for his ideas about benchmarking, to Lorne Olfman, Omar El Sawy, and Kalle Lyytinen for their insights concerning various aspects of the DIS architecture, to the anonymous reviewers for their constructive comments on earlier versions of this paper, and to Vladimir Zwass for his firm support and guidance during the development of this paper.

\section{References}

1. Argyris, C. Overcoming Organizational Defenses: Facilitating Organizational Learning. Boston: Allyn and Bacon, 1990.

2. Armenise P., Bandinelli S., Ghezzi C., and Morzenti A. A Survey and Assessment of Software Process Representation Formalisms. International Journal of Software Engineering and Knowledge Engineering, 3, 3 (1993), 410-426.

3. Band, W. Benchmark Your Performance for Continuous Improvement. Sales \& Marketing Management in Canada, 31, 5 (1990), 36-38.

4. Bansler, J.P., and Bødker, K. A. Reappraisal of Structured Analysis: Design in an Organizational Context. ACM Transactions on Information Systems, 11, 2 (1993), 165-192. 
5. Biesada, A. Benchmarking. Financial World, 160, 19 (1991), 28-32.

6. Biesada, A. Strategic Benchmarking. Financial World, 161, 19 (1992), 30-36.

7. Bødker, S., and Grønbæk, K. Design in Action: From Prototyping by Demonstration to Cooperative Prototyping. In J. Greenbaum and M. Kyng (eds.), Design at Work . Lawrence Erlbaum Associates, $1991,197-$ 218.

8. Boland, R.J. Jr. Information Systems Use as a Hermeneutic Process. In H.-E. Nissen, H.K. Klein and R. Hirschheim (eds.), Information Systems Research: Contemporary Approaches and Emergent Traditions. Elsevier Science, 1991, 439-458.

9. Boynton, A. C., and Victor, B. Beyond Flexibility: Building and Managing the Dynamically Stable Organization. California Management Review (Fall 1991), 53-66.

10. Camp, R. Benchmarking: The Search for Industry Best Practices That Lead to Superior Performance. Wisconsin: ASQC Quality Press, 1989.

11. Camp, R. Learning from The Best Leads to Superior Performance. Journal of Business Strategy, 13, 3 (1992), 3-6.

12. Ciborra, C.U., and Lanzara G.F. Formative Contexts and Information Technology. Accounting, Management \& Information Technologies, 4, 2 (1994), 61-86.

13. Curtis, B., Kellner, M., and Over, J. Process Modeling. Communications of the ACM, 35, 9 (1992), 75-90.

14. Davenport, T.H., and Beers, M.C. Managing Information about Processes. Journal of Management Information Systems, 12, 1 (Summer 1995), 57-80.

15. El Sawy, O.A. and Khorshid, H.S. A Design Theory of Virtual Workflows. Research Paper IOM 94-13, School of Business Administration, University of Southern California, 1994.

16. Eriksson, I., Hellman, R., and Nurminen, M. I. A Method for Supporting Users' Comprehensive Learning. Education \& Computing, 4, 4 (1988), 251-264.

17. Eriksson, I., and Nurminen, M. I. Doing by Learning: Embedded Application Systems. Journal of Organizational Computing, 1, 4 (1991), 323-339.

18. Giddens A. Central Problems in Social Theory: Action, Structure and Contradiction in Social Analysis. Berkeley, CA: University of California Press, 1979.

19. Giddens A. The Constitution of Society. Cambridge, UK: The Polity Press, 1984.

20. Giddens A. Structuration Theory: Past, Present and Future. In C. G. A. Bryant and D. Jary, (Eds.), Giddens' Theory of Structuration, A Critical Approach. London: Routledge and Kegan, 1991, 201-221.

21. Gogg, T.J., and Mott, J.R.A. Improve Quality and Productivity with Simulation ( $3^{\text {rd }}$ Edition). JMI Consulting Group, 1996.

22. Hammer, M., and Champy, J. Reengineering the Corporation: A Manifesto for Business Revolution. New York: HarperCollins Publishers, 1993.

23. Harkleroad, D. Competitive Intelligence: A New Benchmarking Tool. Management Review, 81, 10 (1992), 2629.

24. Harrington, J. Business Process Improvement, New York: McGraw-Hill, 1991, 217-247.

25. Heidegger, M. The Question Concerning Technology. Harper \& Row, New York, 1977.

26. Hellman, R. User Support: Revealing Structure Instead of Surface. Behaviour \& Information Technology, 8, 6 (1989), 417-435.

27. Hutton, R., and Zairi, M. Effective Benchmarking Through a Prioritization Methodology. Total Quality Management, 6, 4 (1995), 399-411.

28. Jennings, R. Using Access ${ }^{\mathrm{TM}}$ for Windows ${ }^{\mathrm{TM}}$. Carmel, IN: Que Corporation, 1993.

29. Jennings, K. and Westfall F. Benchmarking for Strategic Action. Journal of Business Strategy, 13, 3 (1992), 22-25.

30. Kogut, B., and Zander U. Knowledge of the Firm, Combinative Capabilities, and the Replication of Technology. Organization Science, 3, 3, 383-397.

31. Koota, K. Tietojärjestelmien käyttäminen CSCW-prosesseissa organisaation oppimisen ja tiedonluonnin tukena. Pro Gradu-tutkielma. Turun Yliopisto, Tietojenkäsittelyoppi, 1995.

32. Koota, K., and Käkölä, T. Knowledge Creation Nets: A Process Modeling Language for the Dual Information Systems Architecture. University of Jyväskylä, Department of Computer Science and Information Systems, 1998.

33. Käkölä, T. Increasing the Interpretive Flexibility of Information Systems through Embedded Application Systems. Accounting, Management \& Information Technologies, 5,1 (1995), 79-102.

34. Käkölä, T. Evaluation of an Embedded Application System for Supporting Organizational Working and Learning. Proceedings of the 18th IRIS Conference "Design in Context." Gothenburg Studies in Informatics, Report 7, June 1995, 341-358. 
35. Käkölä, T. Designing and Deploying Coordination Technologies for Fostering Organizational Working and Learning: From Vision to Reality? Scandinavian Journal of Information Systems, 7, 2 (1995), 45-74.

36. Käkölä, T., and Koota, K. Dual Information Systems: Supporting Organizational Working and Learning by Making Organizational Memory Transparent. Forthcoming in Journal of Organizational Computing and Electronic Commerce.

37. Lyytinen, K.J., and Ngwenyama, O. K. What Does Computer Support for Cooperative Work Mean? A Structurational Analysis of Computer Supported Cooperative Work. Accounting, Management \& Information Technologies, 2, 1 (1991), 19-37.

38. Malone, T.W. Designing Organization Interfaces. Proceedings of CHI '85 Human Factors in Computing Systems, 66-71. New York: ACM, 1985.

39. Maturi, R. Benchmarking: The Search for Quality. The Financial Manager 3, 2 (1990), 26-31.

40. Miller, J. Measuring Progress Through Benchmarking. CMA Magazine, 66, 5 (1992a), 37.

41. Miller, J. Benchmarking Performance. CMA Magazine, 66, 6 (1992b), 23.

42. Mumford, E. Designing Human Systems. Manchester Business School, 1983.

43. Nonaka I. A Dynamic Theory of Organizational Knowledge Creation. Organization Science, 5, 1 (1994), 1437.

44. Nurminen, M. I. People or Computers: Three Ways of Looking at Information Systems. Lund, Sweden: Studentlitteratur \& Chartwell-Bratt, 1988.

45. O’Neill, P. and Smith P. The Quality Struggle - from Two Angles. Financial Executive, 7, 3 (1991), 51-60.

46. Orlikowski, W. The Duality of Technology: Rethinking the Concept of Technology in Organizations. Organization Science, 3, 3 (1992), 398-427.

47. Peterson, J.L. Petri Net Theory and the Modeling of Systems. Englewood Cliffs, NJ: Prentice Hall, 1981.

48. Rein, G. Organization Design Viewed as a Group Process Using Coordination Technology. Ph.D. dissertation. Austin, Texas: MCC Technical Report CT-039-92, 1992.

49. Roberts J., and Scapens R. Accounting Systems and Systems of Accountability: Understanding Accounting Practices in their Organizational Context. Accounting, Organizations, and Society, 10, 4, (1985), 443-456.

50. Robson, G. D. Continuous Process Improvement: Simplifying Work Flow Systems. New York: Free Press, 1991.

51. Roos, L. L. Jr., and Starke, F. A. Organizational Roles. In P. C. Nyström and W.H. Starbuck (eds.), Handbook of Organizational Design, Vol. 1: Adapting organizations to their environments. Oxford: Oxford University Press, 1981, 290-308.

52. Schmidt, J. The Link Between Benchmarking and Shareholder Value. Journal of Business Strategy, 13, 3 (1992a), 7-13.

53. Schmidt, J. A Tool to Be Best-in-Class. Directors \& Boards, 16, 13 (1992b), 29-35.

54. Serafeimidis, V., and Smithson, S. The Management of Change for a Rigorous Appraisal of IT Investment: The Case of a UK Insurance Organization. Proceedings of the 3rd European Conference on Information Systems, 1995, 221-233.

55. Sharman, P. Benchmarking: Opportunity for Accountants. CMA Magazine, 66, 6 (1992), 16-18.

56. Shepetuk, A. Is Your Product Development Process A Tortoise or A Hare? Management Review, 80, 3 (1991), 25-27.

57. Spendolini, M.J. The Benchmarking Book. New York: American Management Association, 1992.

58. Stryker, S., and Statham, A. Symbolic Interaction and Role Theory. In G. Lindsey and E. Aronson (eds.): Handbook of Social Psychology, Vol. 1. New York: Random House, 1985.

59. Tucker, F.; Zivan, S.; and Camp, R. How to Measure Yourself Against The Best. Harvard Business Review, 65, 1 (1987), 8-10.

60. Tuominen, K. Benchmarking - Yhteenveto Yritysjohdolle. Metalliteollisuuden Keskusliitto, 1993.

61. Vanharanta, H., Käkölä, T., and Back, B. Validity and Utility of a Hyperknowledge-Based Financial Benchmarking System. Proceedings of the 28th Annual Hawaii International Conference on System Sciences (HICSS), Vol. 3, 221-230, IEEE, 1995.

62. Vanharanta , H., Käkölä, T., and Kangas, K. Usability of a Hyperknowledge-Based Executive Support System for Financial Benchmarking. Proceedings of the 28th Annual Hawaii International Conference on System Sciences (HICSS), Vol. 3, 130-139, IEEE, 1995.

63. Winograd, T. and Flores, F. Understanding Computers and Cognition: A New Foundation for Design. Ablex Publishing Corporation, Norwood, NJ, 1986.

64. Zairi, M. Competitive Benchmarking: An Executive Guide. England: Technical Communications LTD., 1992.

65. Zuboff, S. In the Age of the Smart Machine - The Future of Work and Power. Oxford: Heinemann Professional Publishing Ltd, 1988. 